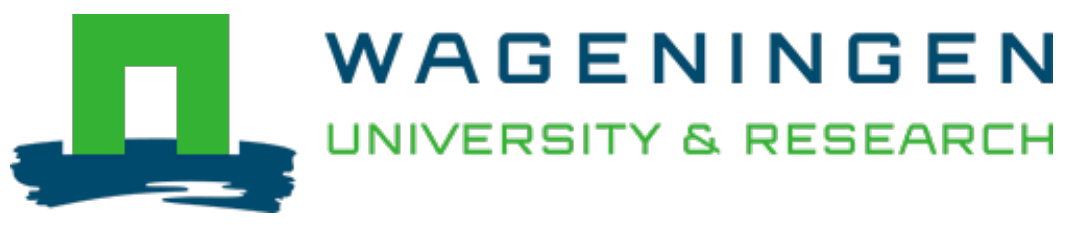

\author{
Behaviour of Staphylococcus aureus during sufu production at laboratory scale \\ Food Control \\ Han, B.; Sesenna, B.; Beumer, R.R.; Nout, M.J.R. \\ https://doi.org/10.1016/j.foodcont.2004.03.001
}

This publication is made publicly available in the institutional repository of Wageningen University and Research, under the terms of article $25 \mathrm{fa}$ of the Dutch Copyright Act, also known as the Amendment Taverne. This has been done with explicit consent by the author.

Article $25 \mathrm{fa}$ states that the author of a short scientific work funded either wholly or partially by Dutch public funds is entitled to make that work publicly available for no consideration following a reasonable period of time after the work was first published, provided that clear reference is made to the source of the first publication of the work.

This publication is distributed under The Association of Universities in the Netherlands (VSNU) 'Article $25 \mathrm{fa}$ implementation' project. In this project research outputs of researchers employed by Dutch Universities that comply with the legal requirements of Article $25 \mathrm{fa}$ of the Dutch Copyright Act are distributed online and free of cost or other barriers in institutional repositories. Research outputs are distributed six months after their first online publication in the original published version and with proper attribution to the source of the original publication.

You are permitted to download and use the publication for personal purposes. All rights remain with the author(s) and / or copyright owner(s) of this work. Any use of the publication or parts of it other than authorised under article $25 \mathrm{fa}$ of the Dutch Copyright act is prohibited. Wageningen University \& Research and the author(s) of this publication shall not be held responsible or liable for any damages resulting from your (re)use of this publication.

For questions regarding the public availability of this publication please contact openscience.library@wur.nl 


\title{
Behaviour of Staphylococcus aureus during sufu production at laboratory scale
}

\author{
Bei-Zhong Han ${ }^{\text {a,b }}$, Barbara Sesenna ${ }^{\text {a }}$, Rijkelt R. Beumer ${ }^{\text {a }}$, M.J. Robert Nout ${ }^{\text {a,* }}$ \\ ${ }^{a}$ Laboratory of Food Microbiology, Department of Agrotechnology and Food Sciences, Wageningen University, P.O. Box 8129, \\ EV 6700 Wageningen, The Netherlands \\ ${ }^{\mathrm{b}}$ College of Food Science and Nutritional Engineering, China Agricultural University, Beijing 100083, China
}

Received 9 December 2003; received in revised form 1 March 2004; accepted 1 March 2004

\begin{abstract}
Sufu is a Chinese soybean cheese, obtained by fungal fermentation of soybean curd (tofu) with Actinomucor elegans to yield pehtze, followed by enzymatic maturation in brine solution containing $12-16 \%(\mathrm{w} / \mathrm{w})$ of $\mathrm{NaCl}$ for $2-6$ months. After equilibration, the final product, sufu, usually contains half of the $\mathrm{NaCl}$ concentration of the brine used. We studied the behaviour (survival, growth, formation of enterotoxins) of several strains of Staphylococcus aureus in a laboratory-scale simulation of the production of sufu. Of $15 \mathrm{~S}$. aureus strains tested, strains No. 1, 3, 4, 5, 8, 9, and 10 showed good growth in sterile Brain Heart Infusion broth with high $(6-12 \%$ w/w) $\mathrm{NaCl}$ concentration, demonstrating their halotolerance. $S$. aureus growth was not negatively influenced by $A$. elegans, and no interaction between the mould and the bacterial strains was observed during pehtze preparation. $S$. aureus strains No. 3 and 5 were selected for maturation experiments because they grew up to 8.9-9.5 log cfu/g and they produced their typical enterotoxin in all substrates tested. With the objective of creating a worst-case scenario, halotolerant enterotoxin producing $S$. aureus strains were inoculated at several stages of the sufu model system. Levels of $6 \%$ and $12 \%$ of $\mathrm{NaCl}$ in the brine solution were still too low to inhibit their growth and enterotoxin production. Even $18 \%$ of $\mathrm{NaCl}$ in the brine solution could not inhibit their growth, but enterotoxin production was prevented. Brine solution with $24 \%$ of $\mathrm{NaCl}$ inhibited growth as well as enterotoxin production. In conclusion, a salt concentration of $9 \%$ in the final product will be a minimum safeguard against $S$. aureus enterotoxin formation.
\end{abstract}

(C) 2004 Elsevier Ltd. All rights reserved.

Keywords: Safety; Tofu; Pehtze; Brine; Actinomucor elegans; Enterotoxin; Salt tolerance

\section{Introduction}

Sufu is a Chinese soybean cheese, normally made by solid-state fungal fermentation of soybean curd (tofu) with Actinomucor elegans, followed by salting and maturation in brine dressing mixtures containing salt, alcohol and various other ingredients ( $\mathrm{Su}, 1986)$. The maturation could take 2-6 months to be completed (Han, Rombouts, \& Nout, 2001b), yielding sufu containing $8-14 \%(\mathrm{w} / \mathrm{w})$ of $\mathrm{NaCl}$ and some ethanol. For public health reasons and to shorten the ripening period, it is of interest to reduce salt levels in sufu.

Similar to some other fermented foods such as cheese (Messens, Dewettinck, \& Huyghebaert, 1999) and miso

\footnotetext{
${ }^{*}$ Corresponding author. Tel.: +31-317-482834; fax: +31-317484978.

E-mail address: rob.nout@wur.nl (M.J. Robert Nout).
}

(Chiou, Ferng, \& Beuchat, 1999), salt plays a very important role in sufu. It imparts a salty taste to the product, serves to control the enzyme activity, and it inhibits the survival and/or growth of spoilage-causing, pathogenic and toxin-producing microorganisms. Lowering the salt content could thus cause a reduction of safety.

Staphylococcus aureus is a halo-tolerant pathogenic bacterium, often associated with human skin. It occurs in commercial tofu (Van Kooij \& De Boer, 1985), and is likely to be present in sufu as this involves manual operations on tofu. Several kinds of sufu samples obtained from different markets and factories in China and The Netherlands were analysed (Han, Beumer, Rombouts, \& Nout, 2001a). These authors failed to detect viable $S$. aureus in the samples tested because competitive microflora (mainly bacilli) prevented the formation of typical colonies on agar plates during the incubation 
of $S$. aureus. Qualitative detection tests for staphylococcal enterotoxins in sufu samples showed that some containing $14 \% \mathrm{w} / \mathrm{w}$ salt and $0.5 \% \mathrm{w} / \mathrm{w}$ ethanol, contained staphylococcal enterotoxin A. Other enterotoxins (B, C, D, and E) were below the level of detection.

During the traditional sufu production process the product is subject to contamination from equipment, handling, substandard inoculum, etc. Tofu cubes are heated at $100{ }^{\circ} \mathrm{C}$ for $10-15 \mathrm{~min}$ to reduce the moisture content to about $70 \%$, firming-up their consistency, and pasteurizing the cubes before they are inoculated (Nout \& Aidoo, 2002). Whereas at this stage the resulting product is safe from $S$. aureus and its enterotoxin, contamination may occur during later stages such as mould starter inoculation, addition of brine solution, and final packaging.

Shi and Fung (2000) studied the behaviour of several foodborne pathogens during sufu fermentation and aging. They demonstrated that $S$. aureus inoculated into non-sterile samples of sufu at 3-5 log cfu/g were able to grow up to 7-9 $\log \mathrm{cfu} / \mathrm{g}$ after 2 days of mould fermentation. The starter culture of $A$. elegans did not significantly inhibit bacterial growth. The aging solution traditionally used for the maturation period $(10 \%$ alcohol $+12 \% \mathrm{NaCl}$ ) was effective in controlling $S$. aureus growth, and after 1 month of aging pathogens were no longer detectable. It was demonstrated that $S$. aureus could be effectively killed (Pao, 1995) in a medium containing $10 \%$ of $\mathrm{NaCl}$ and $10 \%$ of ethanol. Since the results of Shi and Fung (Shi \& Fung, 2000) and Pao (Pao, 1995) do not explain the presence of enterotoxin A in occasional commercial sufu, we devised a "worstcase" scenario in which $S$. aureus were selected for halotolerance and capability to produce enterotoxins.

The present study quantifies the survival, growth, and formation of enterotoxins by halotolerant strains of $S$. aureus in a model system that simulates sufu production.

\section{Materials and methods}

\subsection{Microorganisms}

A pure culture of A. elegans, strain LU 2025 (Chinese sufu starter) was used in this research.

Strains of $S$. aureus were provided by Wageningen University. The strains were grown in Brain Heart Infusion (BHI, Oxoid CM225) at $37{ }^{\circ} \mathrm{C}$ for $24 \mathrm{~h}$, and diluted in PPS (8.5 g NaCl and $1 \mathrm{~g}$ Neutralised Bacteriological Peptone (Oxoid L34) per liter) to obtain levels of 3-4 $\log \mathrm{cfu} / \mathrm{ml}$ to be used as experimental inoculum.

\subsection{Selection of halotolerant $S$. aureus}

Strains were selected for halotolerance by measuring their growth in sterile BHI to which $0 \%, 3 \%, 6 \%, 9 \%$ and
$12 \%(\mathrm{w} / \mathrm{v}) \mathrm{NaCl}$ had been added. Growth was measured by optical density at $620 \mathrm{~nm}$ using a microtiter reader (340 ATTC, SLT Labinstruments, Austria). Each microwell contained $200 \mu \mathrm{l}$ of BHI-salt solution, and $20 \mu \mathrm{l}$ of $S$. aureus at 3-4 $\log \mathrm{cfu} / \mathrm{ml}$. Each well was covered by one drop of sterile paraffin to protect against contamination and excessive evaporation. Growth was measured at chamber temperature $37^{\circ} \mathrm{C}$ every 15 min during $24 \mathrm{~h}$.

\subsection{Detection of staphylococcus enterotoxins $A, B, C, D$ and $E$}

The detection of staphylococcal enterotoxins A, B, C, $\mathrm{D}$ and $\mathrm{E}$ was carried out by enzyme immunoassay (RIDASCREEN $^{\circledR}$ SET A, B, C, D, E; Art. No.: R 4101, R-Biopharm GmbH, Germany) (Park, Akhtar, \& Rayman, 1994). In accordance with the manufacturer's instructions, samples that gave an absorbance at $450 \mathrm{~nm}$ that was less than the cut-off value were reported as negative. Samples giving an absorbance at $450 \mathrm{~nm}$ equal to or greater than the cut-off value were reported as positive. The samples were distributed at random in the microtiter plate to avoid any interference.

\subsection{VIDAS staph enterotoxin (SET) assay}

The VIDAS Assay is an enzyme-linked fluorescent immunoassay (ELFA) performed with the automated VIDAS (BioMérieux, Marcy l'Etoile, France) instrument for the non-specific detection of the presence of any staphylococcal enterotoxins. Fluorescence is measured twice in the Reagent Strip's optical cuvette for each specimen tested. The first reading is a background reading of the substrate cuvette before the solid phase receptacle (SPR) is introduced into the substrate. The second reading is taken after incubating the substrate with the enzyme remaining on the interior of the SPR. The relative fluorescence value RFV is calculated by subtracting the background reading from the final result. This calculation appears on the result sheet. The RFV obtained for each sample is interpreted by VIDAS as follows: Test Value $=$ sample RFV/standard RFV. Test values are compared to a threshold value of 0.13 ; test values exceeding the threshold are considered positive (i.e. enterotoxins present). The detection limit is 1 $\mathrm{ng} / \mathrm{ml}$.

\section{5. $\mathrm{NaCl}$ content of sufu}

Tenfold diluted sufu was titrated with $0.1 \mathrm{M} \mathrm{AgNO}_{3}$, and $10 \%(\mathrm{w} / \mathrm{v}) \mathrm{K}_{2} \mathrm{CrO}_{4}$ solution was used as an indicator. The following equation was used: $\%$ Salt as $\%(w / w)$ $\mathrm{NaCl}=V * M * 0.0584 * 100 / \mathrm{m}$; where $V$ and $M$ are the volume and molarity of $\mathrm{AgNO}_{3}$ used, and $m$ is the mass of fresh sample. 


\subsection{Preparation of experimental sufu and its intermediate products}

Tofu, pehtze, and sufu used in this investigation were prepared following an adapted laboratory scale protocol (Han, Wang, Rombouts, \& Nout, 2003).

Firm tofu was prepared as a substrate for fermentation using dehulled soybeans (Golden Wonder, USA, from Kleinjan VFO, Rhoon, The Netherlands). Soybeans (600 g) were soaked in tap water overnight; after rinsing the soaked beans were ground with hot water (water:bean ratio $6: 1$ ) and soymilk was obtained after sieving and was brought to the boil. After cooling the milk to $70^{\circ} \mathrm{C}$, tofu was obtained by coagulation using $12 \mathrm{~g} \mathrm{CaSO}_{4}$. Tofu cake was cut into cubes of size $3.2 \times 3.2 \times 1.6 \mathrm{~cm}$. The cubes were placed in jars containing 3 pieces each, and sterilized at $121{ }^{\circ} \mathrm{C}$ for $15 \mathrm{~min}$. After cooling, the cubes were dipped in a 4-5 $\log \mathrm{cfu} / \mathrm{g}$ spore suspension of $A$. elegans. After replacing the inoculated cubes in the jars, these were incubated for $48 \mathrm{~h}$ at $30^{\circ} \mathrm{C}$ to allow the mould fermentation to take place, i.e. to obtain pehtze.

\subsection{Growth and enterotoxin production of $S$. aureus in tofu in presence or not of $A$. elegans, and on pehtze}

In practice, $S$. aureus contamination may occur during handling of tofu during inoculation by spraying or dipping in the mould spore suspension. S. aureus growth was checked in tofu in the presence as well as absence of A. elegans, to detect if the mould would inhibit the growth of $S$. aureus after artificial contamination at levels of 3-4 log cfu/g. The incubation temperature (37 ${ }^{\circ} \mathrm{C}$ ) for the inoculated tofu cubes was chosen so as to be optimum for $S$. aureus. An incubation temperature of 30 ${ }^{\circ} \mathrm{C}$ was also used in the experiment for tofu inoculated with the mould and artificially contaminated with $S$. aureus. This temperature is the optimum for A. elegans growth; so it could be observed if this parameter may have some positive influence on the mould growth, or a negative effect on $S$. aureus.

After fermentation of tofu with A. elegans, pehtze cubes are densely overgrown by the fungal mycelium. The long white hyphae need to be flatted to form a kind of skin around the cubes, which soften during maturation. In the traditional process this is a manual operation, so it may be a source of contamination of $S$. aureus. For this study, pehtze was artificially contaminated with S. aureus (3-4 log cfu/g), and incubated at $37^{\circ} \mathrm{C}$ for $24 \mathrm{~h}$. For each experiment, triplicate samples were taken for the detection of enterotoxins A, B, C, D and E.

\subsection{S. aureus behaviour in sufu during one month of maturation in brine solutions of different salt content}

Based on the results of previous experiments mentioned earlier, two strains (No. 3 and 5) of S. aureus were selected and used for the maturation treatment since they were able to grow and produce their own typical enterotoxins in all intermediate products (tofu and pehtze).

Four different brine solutions were prepared by sterilizing $\mathrm{NaCl}$ solutions for $15 \mathrm{~min}$ at $121{ }^{\circ} \mathrm{C}$, followed by aseptic addition of $10 \%(\mathrm{w} / \mathrm{v})$ ethanol. In this way, four brine solutions with respectively $6 \%, 12 \%, 18 \%$, and $24 \%$ (w/v) $\mathrm{NaCl}$ containing also $10 \%(\mathrm{w} / \mathrm{v})$ ethanol were obtained. Empty screw-capped $250 \mathrm{ml}$ glass jars were filled with 2 tofu cubes of $10 \mathrm{~g}$ each, and were sterilized for $15 \mathrm{~min}$ at $121^{\circ} \mathrm{C}$. After inoculation with spore suspension of $A$. elegans at 4-5 $\log \mathrm{cfu} / \mathrm{ml}$ and incubation for $48 \mathrm{~h}$ at $30{ }^{\circ} \mathrm{C}$, the mould hyphae of pehtze were first smoothed down by sterile spatula and then inoculated by dipping $30 \mathrm{~s}$ into suspensions of 4-5 $\log \mathrm{cfu} / \mathrm{ml}$ of the selected strains of $S$. aureus. The jars were weighed to determine the amount of brine solution that should be added, to obtain a proportion 1:1 with the pehtze cubes. Samples were collected for the enterotoxins and growth analysis at $t=0$. The jars were incubated at $37{ }^{\circ} \mathrm{C}$. Treatments, as well as a negative control, were analyzed after 2 weeks $(t=2)$, and after 4 weeks $(t=4)$.

\section{Results and discussion}

\subsection{Selection for halotolerance}

The results summarized in Table 1 demonstrate that most strains were able to grow in $0 \%$ and $3 \%$, and eight strains still grow in 9\% salt. Strains No. 3 and 4 were able to grow fairly well in $12 \% \mathrm{w} / \mathrm{v} \mathrm{NaCl}$. The type of enterotoxins produced in Brain Heart Infusion broth without added salt are mentioned in this table. In order to have test strains able to produce a wide spectrum of enterotoxins, strains No. 1, 3, 4, 5, 8, 9, and 10 were selected for further examination.

\subsection{Staphylococcus aureus behaviour in tofu and pehtze}

Staphylococcus aureus behaviour in tofu and pehtze is shown in Table 2. The environmental conditions chosen for $S$. aureus in this experiment were optimum for the microorganism: $\mathrm{pH}$ of sterile tofu was 6.0 , incubation temperature of $37^{\circ} \mathrm{C}$, and no competition with other microorganisms, except $A$. elegans that could have negative influence. From Table 2, it can be observed that $S$. aureus growth was not negatively influenced by the presence of $A$. elegans, reaching a level of $9 \log \mathrm{cfu} / \mathrm{g}$. Growth of $S$. aureus on tofu with $A$. elegans, incubated at $30{ }^{\circ} \mathrm{C}$, gave similar results as at $37{ }^{\circ} \mathrm{C}$ (data not shown). After inoculation of pehtze ( $\mathrm{pH} 7.1$ of pehtze, even more suitable for $S$. aureus), $S$. aureus again reached $9 \log \mathrm{cfu} / \mathrm{g}$. The behaviour of $A$. elegans was also monitored; visual inspection revealed unaltered 
Table 1

Growth of $S$. aureus strains in Brain Heart Infusion broth with different added salt concentrations, incubated at $37{ }^{\circ} \mathrm{C}$ for $24 \mathrm{~h}$

\begin{tabular}{|c|c|c|c|c|c|c|c|}
\hline \multirow[t]{2}{*}{ S. aureus No. } & \multirow[t]{2}{*}{ Strain codes } & \multicolumn{5}{|c|}{$\mathrm{NaCl}$} & \multirow{2}{*}{$\begin{array}{l}\text { Enterotoxin forming } \\
\text { ability }(\mathrm{BHI}, 0 \% \mathrm{NaCl})\end{array}$} \\
\hline & & $0 \%$ & $3 \%$ & $6 \%$ & $9 \%$ & $12 \%$ & \\
\hline 1 & $01-1122$ & + & + & \pm & \pm & 0 & $\mathrm{~A}^{\mathrm{a}}$ \\
\hline 2 & $01-973$ & + & + & + & $\overline{0}$ & 0 & A \\
\hline 3 & $02-55$ & + & + & + & + & \pm & A \\
\hline 4 & $02-24$ & ++ & + & + & \pm & \pm & A \\
\hline 5 & $326 \mathrm{E}$ & + & + & \pm & \pm & 0 & $\mathrm{E}$ \\
\hline 6 & $01-98$ & + & + & 0 & 0 & 0 & $\mathrm{D}$ \\
\hline 7 & $01-1224$ & + & \pm & \pm & 0 & 0 & A, B \\
\hline 8 & $01-899$ & + & + & + & \pm & 0 & B \\
\hline 9 & 01-893 & + & + & \pm & \pm & 0 & $\mathrm{C}$ \\
\hline 10 & $01-254$ & + & + & \pm & \pm & 0 & A, D \\
\hline 11 & $196 \mathrm{E}$ & \pm & \pm & 0 & 0 & 0 & A \\
\hline 12 & 14458 & \pm & \pm & 0 & 0 & 0 & B \\
\hline 13 & $137 \mathrm{C}$ & + & \pm & \pm & \pm & 0 & $\mathrm{C}$ \\
\hline 14 & 1183 & + & + & 0 & 0 & 0 & $\mathrm{~F}$ \\
\hline
\end{tabular}

$0=$ No growth $\left(\mathrm{OD}_{620} 0.0-0.10\right) ; \pm=$ light growth $\left(\mathrm{OD}_{620} 0.11-0.30\right) ;+=$ growth $\left(\mathrm{OD}_{620} 0.31-0.70\right) ;++=$ heavy growth $\left(\mathrm{OD}_{620} \geqslant 0.71\right)$. All data are based on averages of triplicate microwells, after correction with blanks of the same $\mathrm{NaCl}$ content.

${ }^{a}$ Type of staphylococcal enterotoxin that was detected by Ridascreen ${ }^{\circledR}$.

Table 2

$S$. aureus growth $(\log \mathrm{cfu} / \mathrm{g})$ and enterotoxin production after inoculation at 3-4 log cfu/ml in different substrates

\begin{tabular}{llll}
\hline S. aureus No. & Tofu & Tofu with A. elegans & Pehtze \\
\hline 1 & 9.0 & 9.6 & $9.4 \mathrm{C}^{\mathrm{a}}$ \\
3 & $9.0 \mathrm{~A}$ & $9.2 \mathrm{~A}$ & $9.3 \mathrm{~A}$ \\
4 & 8.9 & 9.1 & 9.2 \\
5 & $9.2 \mathrm{E}$ & $9.1 \mathrm{E}$ & $9.2 \mathrm{E}$ \\
8 & 9.0 & 9.3 & 9.3 \\
9 & 8.9 & 9.4 & $9.3 \mathrm{C}$ \\
10 & $9.1 \mathrm{D}$ & $9.4 \mathrm{D}$ & $9.4 \mathrm{D}$ \\
Negative control $^{\mathrm{b}}$ & $<1.7$ & $<1.7$ & $<1.7$ \\
\hline
\end{tabular}

All treatments were incubated for $24 \mathrm{~h}$ at $37^{\circ} \mathrm{C}$.

${ }^{\mathrm{a}}$ Type of staphylococcal enterotoxin that was detected by Ridascreen $^{\circledR}$.

${ }^{\mathrm{b}}$ The negative control was performed to check possible contamination.

mycelial development, whereas the extent of sporulation-measured by plate counting - was at the same level ( $>6 \log \mathrm{cfu} / \mathrm{g}$ ) with or without artificial inoculation with $S$. aureus. Consequently, no interaction between the mould and the bacteria takes place.

\subsection{Detection of staphylococcal enterotoxins in tofu and pehtze}

Table 2 shows the types of staphylococcal enterotoxins that were detectable (absorbance higher than the cut-off value) in the Ridascreen ${ }^{\circledR}$ immunoassay. The detection limit of this assay is $0.2-0.7 \mathrm{ng} / \mathrm{ml}$. Even though $S$. aureus could grow to $9 \log \mathrm{cfu} / \mathrm{g}$, not all strains were producing their enterotoxins in the substrate and one strain (1) appeared to produce a different enterotoxin on pehtze (C) than in BHI (A). Of the seven halotolerant strains tested, only stains No. 1, 3, 5, 9, and
10 produced enterotoxins. Strains No. 1 and 9 only produced enterotoxin in pehtze. Strain No. 10 produced only enterotoxin D, instead of A and D in BHI. Only strains No. 3 and 5 are fairly salt tolerant (Table 1) and produced their typical enterotoxin in all processing stages. For that reason, these were selected for the maturation experiment. Taking into account the detection limit and dilutions used in the test, positive results represent enterotoxin levels of at least 1-2 ng/g of food. Since the amount of enterotoxin required to cause illness is probably at least $100 \mathrm{ng}$ of enterotoxin A (the serotype most involved in foodborne staphylococcal illness) (Evenson, Hinds, Bernstein, \& Bergdoll, 1988), tests should be able to detect about $100 \mathrm{ng}$ in $100 \mathrm{~g}$ of food product. Consequently, the levels found in our experiment could represent hazardous situations.

\subsection{Behaviour of S. aureus strains No. 3 and 5 in sufu during one month of maturation}

$S$. aureus growth during the maturation period showed a very clear response towards different salt concentrations as shown in Table 3 . After 2 weeks at 37 ${ }^{\circ} \mathrm{C}, \mathrm{S}$. aureus exceeded $7 \mathrm{log} \mathrm{cfu} / \mathrm{g}$ except in brine containing $24 \% \mathrm{NaCl}$ and $10 \%$ ethanol in which both strains died. Since salt is equilibrated between the brine and the product, it can be assumed that with the latter brine a level of $12 \%$ of salt is present in the sufu. These data are in agreement with the screening test for halotolerance, which showed the capacity of $12 \% \mathrm{NaCl}$ to inhibit the growth of most of the strains. Nevertheless, strain No. 3 was able to survive in BHI containing 12\% salt, but not in sufu after 4 weeks of maturation. BHI is an optimum medium for Staphylococci, whereas the environmental conditions in sufu are different and 
Table 3

$S$. aureus growth (log cfu/g) and enterotoxin production $(+)$ in sufu matured in brines of different compositions, after inoculation $(t=0), 2$ weeks $(t=2)$, and 4 weeks $(t=4)$ of maturation

\begin{tabular}{lllll}
\hline $\begin{array}{l}\text { S. aureus } \\
\text { No. }\end{array}$ & $\begin{array}{l}\text { Initial brine } \\
(\mathrm{NaCl} \%)\end{array}$ & $t=0$ & $t=2$ & $t=4$ \\
\hline 3 & $6 \%$ & 3.7 & $>7+$ & $>7+$ \\
& $12 \%$ & 3.6 & $>7+$ & $>7+$ \\
& $18 \%$ & 3.4 & $>7$ & $>7$ \\
& $24 \%$ & 3.4 & $<1.7$ & $<1.7$ \\
5 & $6 \%$ & 3.5 & $>7+$ & $>7+$ \\
& $12 \%$ & 2.9 & $>7+$ & $>7+$ \\
& $18 \%$ & 3.3 & $>7$ & $>7$ \\
& $24 \%$ & 3.5 & $<1.7$ & $<1.7$ \\
\hline
\end{tabular}

All brines contained $10 \% \mathrm{w} / \mathrm{v}$ ethanol in addition to the $\mathrm{NaCl}$ levels mentioned above. Enterotoxins were detected using the VIDAS SET method.

maybe not the best for $S$. aureus growth or survival. Table 3 also shows the presence of enterotoxins as detected by VIDAS SET assay, at a sensitivity level of 1 $\mathrm{ng} / \mathrm{ml}$. These data show that immediately after inoculation, S. aureus is not yet producing detectable levels of enterotoxins presumably because its inoculum level (3-4 $\log \mathrm{cfu} / \mathrm{ml}$ ) is too low. After 2 weeks of maturation, both strains of $S$. aureus were able to produce detectable levels of enterotoxin in sufu matured in (initially) $6 \%$ and $12 \%$ of $\mathrm{NaCl}$, corresponding with significant growth. After 4 weeks of maturation this situation had not changed. Maturation in brine of $18 \% \mathrm{NaCl}$ and $10 \%$ ethanol prevented enterotoxin production but not growth, which remained at $>7 \log \mathrm{cfu} / \mathrm{g}$. We assume that the brine containing $18 \% \mathrm{NaCl}$ and $10 \%$ ethanol may damage the cytoplasmic membrane and the metabolic system, causing inhibition of enterotoxin production, even though growth was still profuse; this may be similar to the behaviour under osmotic stress. Taking into account this "worst-case" approach for staphylococcal enterotoxins it would appear reasonable to keep $18 \%$ $\mathrm{NaCl}+10 \%$ ethanol as a safe minimum level in maturation brine; this would correspond to $9 \% \mathrm{NaCl}+5 \%$ ethanol in the final product sufu, after equilibration.

\section{Acknowledgements}

The technical assistance by Birgit Hasenack and Wilma Hazeleger is gratefully acknowledged.

\section{References}

Chiou, R. Y. Y., Ferng, S., \& Beuchat, L. R. (1999). Fermentation of low-salt miso as affected by supplementation with ethanol. International Journal of Food Microbiology, 48, 11-20.

Evenson, M. L., Hinds, M. W., Bernstein, R. S., \& Bergdoll, M. S. (1988). Estimation of human dose of staphylococcal enterotoxin A from a large outbreak of staphylococcal food poisoning involving chocolate milk. International Journal of Food Microbiology, 7, 311316 .

Han, B.-Z., Beumer, R. R., Rombouts, F. M., \& Nout, M. J. R. (2001a). Microbiological safety and quality of commercial sufu - a Chinese fermented soybean food. Food Control, 12, 541-547.

Han, B.-Z., Rombouts, F. M., \& Nout, M. J. R. (2001b). A Chinese fermented soybean food. International Journal of Food Microbiology, 65, 1-10.

Han, B.-Z., Wang, J. H., Rombouts, F. M., \& Nout, M. J. R. (2003). Effect of $\mathrm{NaCl}$ on textural changes and protein and lipid degradation during the ripening of sufu, a Chinese fermented soybean food. Journal of the Science of Food and Agriculture, 83, 899-904.

Messens, W., Dewettinck, K., \& Huyghebaert, A. (1999). Transport of sodium chloride and water in Gouda cheese as affected by highpressure brining. International Dairy Journal, 9, 569-576.

Nout, M. J. R., \& Aidoo, K. E. (2002). Asian fungal fermented food. In H. D. Osiewacz (Ed.), The Mycota. Vol. X. Industrial applications (pp. 23-47). Berlin, Heidelberg, New York: Springer-Verlag.

Pao, S.-C. (1995). Halophilic organisms in sufu, Chinese cheese, Dissertation Abstracts International, B55 (10) 4190. Order no. DA9505268, Thesis publ., 1994, 207pp.

Park, C. E., Akhtar, M., \& Rayman, M. K. (1994). Evaluation of a commercial enzyme immunoassay kit (RIDASCREEN) for detection of staphylococcal enterotoxins A, B, C, D, and E in foods. Applied and Environmental Microbiology, 60, 677-681.

Shi, X., \& Fung, D. Y. C. (2000). Control of foodborne pathogens during sufu fermentation and aging. Critical Reviews in Food Science and Nutrition, 40(5), 399-425.

Su, Y.-C. (1986). Sufu. In N. R. Reddy, M. D. Pierson, \& D. K. Salunkhe (Eds.), Legume-based fermented foods (pp. 69-83). Boca Raton, Fl, USA: CRC Press.

Van Kooij, J. A., \& De Boer, E. (1985). A survey of the microbiological quality of commercial tofu in the Netherlands. International Journal of Food Microbiology, 2, 349-354. 